\title{
Combined pediatric heart transplant and Nuss procedure in a patient with Marfan syndrome
}

Teimour Nasirov, MD, ${ }^{\mathrm{a}}$ John C. Dykes, MD, ${ }^{\mathrm{b}}$ Matias Bruzoni, MD, ${ }^{\mathrm{c}}$ and Katsuhide Maeda, MD, ${ }^{\mathrm{a}}$ Stanford, Calif

\footnotetext{
From the Divisions of ${ }^{\mathrm{a}}$ Pediatric Cardiac Surgery, Department of Cardiovascular Surgery, ${ }^{\mathrm{b}}$ Pediatric Cardiology, Department of Pediatrics, Lucile Packard Children's Hospital, and ${ }^{c}$ Pediatric Surgery, Department of Surgery, Stanford University School of Medicine, Stanford, Calif.

Disclosures: Authors have nothing to disclose with regard to commercial support.

Received for publication Oct 28, 2019; revisions received Oct 28, 2019; accepted for publication Nov 16, 2019; available ahead of print Feb 14, 2020.

Address for reprints: John C. Dykes, MD, Stanford University Department of Pediatrics (Cardiology), Lucile Packard Children's Hospital, 750 Welch Rd, Suite 350, Palo Alto, CA 94304 (E-mail: jdykes@stanford.edu). JTCVS Techniques 2020;1:97-9

2666-2507

Copyright (C) 2019 The Authors. Published by Elsevier Inc. on behalf of The American Association for Thoracic Surgery. This is an open access article under the CC BY-NC-ND license (http://creativecommons.org/licenses/bync-nd/4.0/).

https://doi.org/10.1016/j.xjtc.2019.11.002
}

Marfan syndrome is a connective tissue disorder caused by mutation in the FBN1 gene that results in a defect in the fibrillin-1 extracellular matrix protein. The primary cardiovascular complications include aortopathy and mitral valve disease. ${ }^{1}$ Some patients with Marfan syndrome have both pectus deformities and significant aortopathy, both of which may require surgical repair. Although concurrent surgical repair is more complex, the major advantage includes the lack of hemodynamic and respiratory compromise secondary to compression of thoracic organs postoperatively and has become more popular in recent years with excellent outcomes. ${ }^{2,3}$ Due to the risk of vascular complications, the safety for heart transplantation in patients with Marfan syndrome has historically been controversial. However, recent reports demonstrate satisfactory mid- and long-term outcomes. ${ }^{4}$

\section{CASE REPORT}

We present a 9-year-old, 32-kg boy with Marfan syndrome who previously underwent mechanical valve Bentall operation at an outside hospital. The procedure was complicated by left main coronary artery occlusion requiring transfer to our institution and placement of left internal mammary artery to left anterior descending coronary artery bypass graft. Despite patency of this graft, he developed ischemic dilated cardiomyopathy with severe left ventricular dysfunction requiring listing for heart transplant. In addition, our patient had severe pectus excavatum with significant compression of his right atrium and right ventricle (Figures 1 and 2). Fortunately, a heart became available with a donor to recipient weight ratio of 1.9, necessitating concomitant pectus repair with orthotopic heart transplant (OHT). The chest was entered safely, the patient was placed on cardiopulmonary bypass, and cardiac implantation was conducted with standard techniques. The heart was reperfused and weaned off the bypass without any issues.

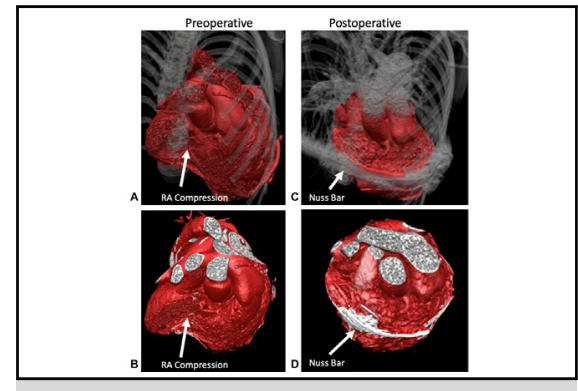

$C T$ 3D reconstruction showing preoperative and postoperative anatomy.

\section{CENTRAL MESSAGE \\ We describe the first combined pediatric orthotopic heart trans- plant and Nuss procedure in a patient with Marfan syndrome.}

See Commentaries on pages 100 and 102.

We then began his pectus excavatum repair using a Nuss bar on the lower end of the sternum the using technique previously described by Casamassima and colleagues.

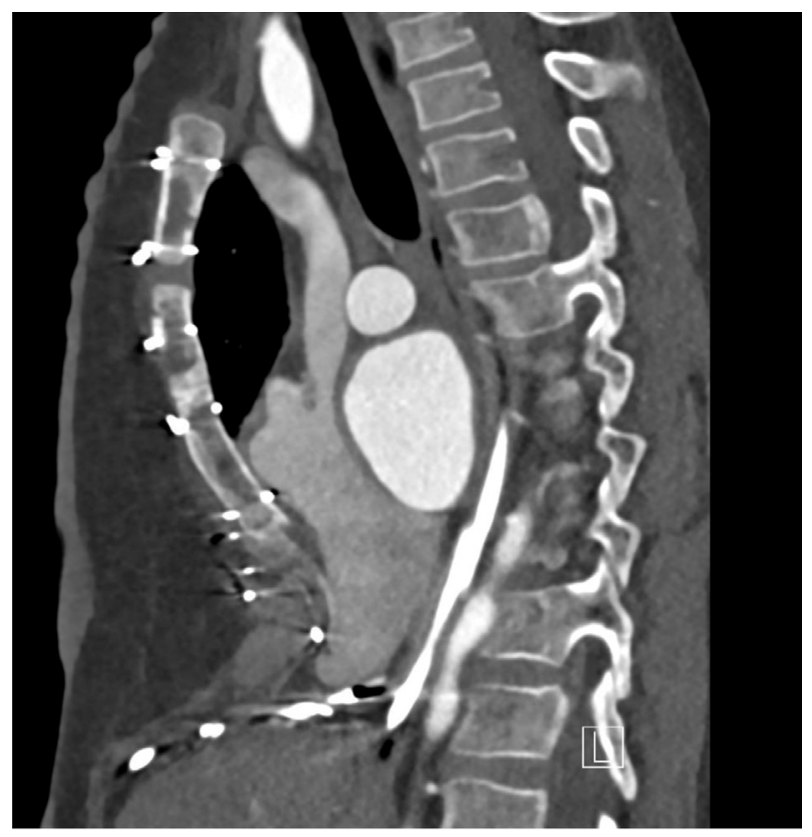

FIGURE 1. Sagittal computed tomography scan showing severe pectus deformity. 


\section{Preoperative}

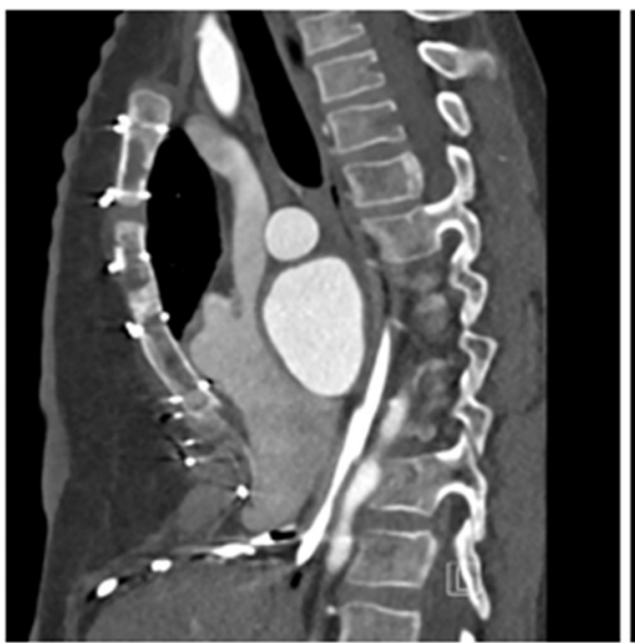

Postoperative

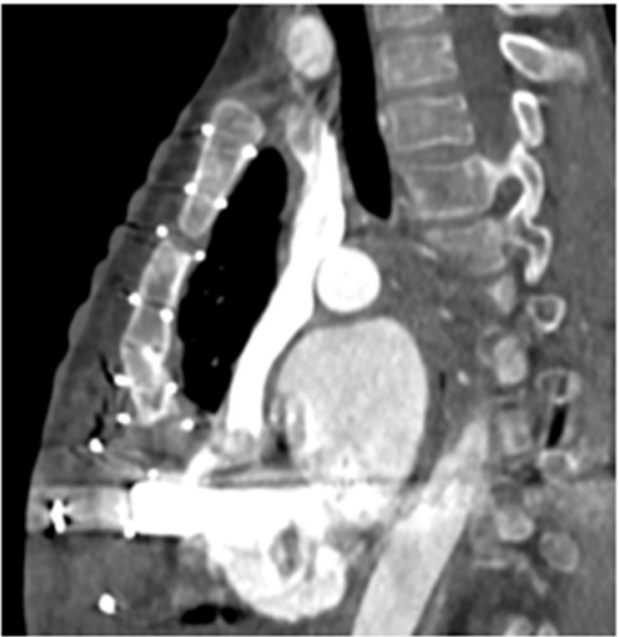

FIGURE 2. Sagittal computed tomography images showing preoperative severe pectus excavatum (left) with significant improvement following Nuss Procedure in postoperative image (right) without compression of transplanted heart.
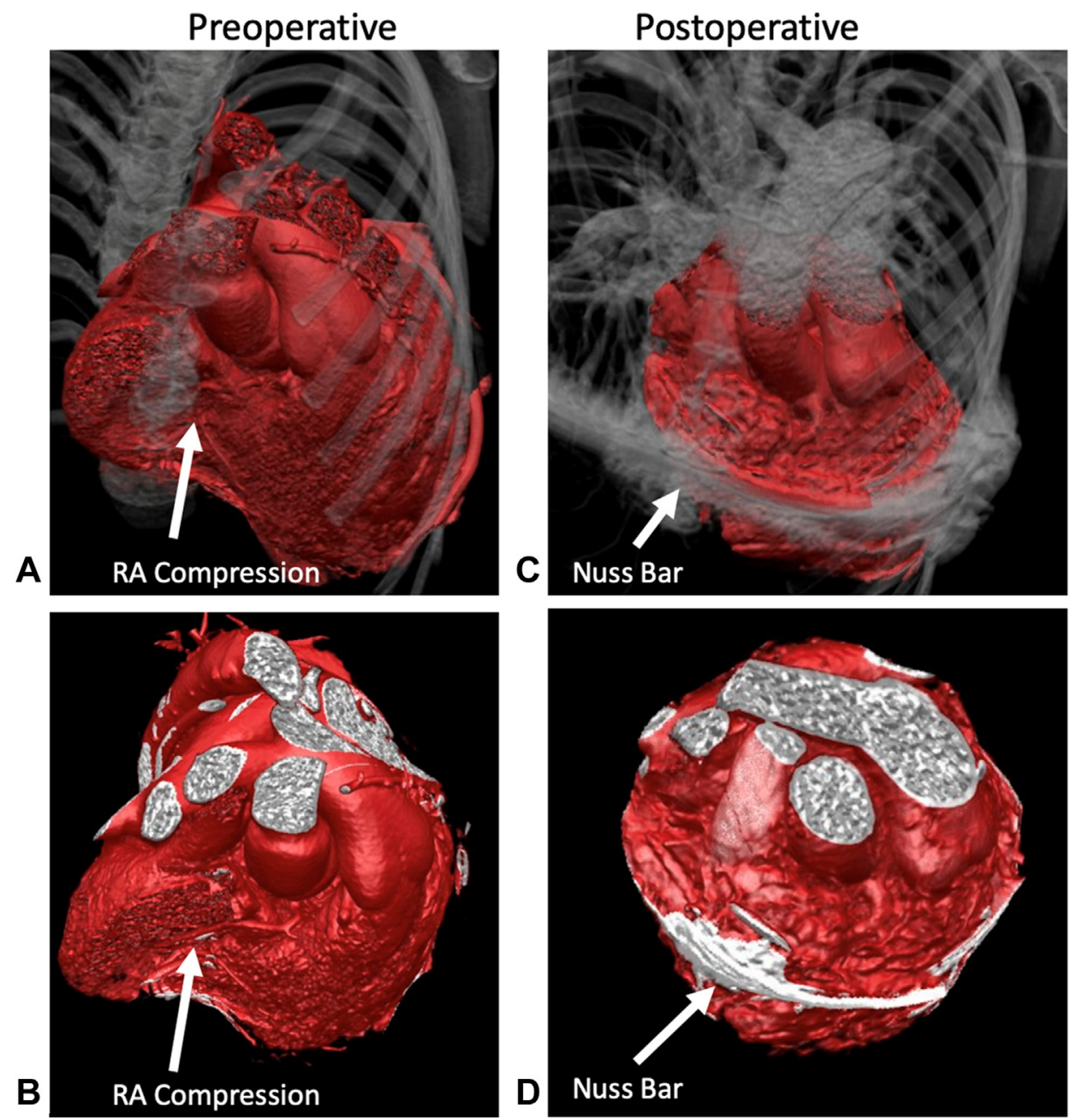

FIGURE 3. Computed tomography 3-dimensional reconstruction showing preoperative and postoperative anatomy. A and B show failing dilated native heart with severe preoperative pectus excavatum. C and D show transplanted heart with stabilization of the chest wall with Nuss Bar. 
Bilateral 2.5-cm transverse thoracic incisions were made in line with the deepest point of the depression in each lateral chest wall between the anterior and midaxillary lines. A skin tunnel was raised anteriorly from both incisions to the top of the pectus ridge at the previously selected intercostal space. An appropriately tailored curved bar (Biomet Microfixation, Jacksonville, Fla) was then passed from one incision to the other across the midline slightly medial to the top of the pectus ridge and deep to the bisected sternum under direct visualization. The bar was then turned to elevate the sternal halves and the anterior chest. Once the sternum was closed, the bar was secured to the ribs with sutures. Figure 3 shows preoperative and postoperative 3-dimensional reconstructions highlighting relief of the right atrium and right ventricle compression. Postoperatively, the child recovered well and was discharged on postoperative day 18 .

\section{COMMENT}

This is the first reported case of a combined Nuss procedure and heart transplant in a patient with Marfan syndrome. This case report highlights a number of important preoperative, intraoperative, and postoperative issues that should be considered performing transplants in this highrisk population. Our rationale for concomitant OHT and Nuss procedure included the following considerations. To maximize the donor pool, we performed a pectus repair that would increase intrathoracic volume and allow for placement of a larger donor heart without cardiac compression. A stepwise approach could not be performed due to our patient's severe heart failure. Placement of a ventricular assist device and repair of the pectus was not favored due to the patient's history of multiple sternotomies, Marfan syndrome with a Bentall operation, and the impending need for a heart transplant requiring an additional sternotomy. Thus, the decision of concomitant OHT with pectus excavatum repair was made in an effort to maximize potential donor size-eligibility due to the significant waitlist mortality risk and unfavorable ventricular assist device options. The plan is to leave the bar in place for 3 years with cardiopulmonary bypass on standby during removal due to the lack of pericardial cushion separating the bar and heart.

This case demonstrates that combined OHT and Nuss procedure is effective in patients with Marfan syndrome and pectus excavatum without significant increased morbidity. It is reasonable to consider this approach in select pediatric heart transplant patients with chest wall deformities to facilitate standard size criteria and limit waitlist time.

We thank Shannon Walters at the Stanford 3D and Quantitative Imaging Laboratory.

\section{References}

1. Landis BJ, Cooper DS, Hinton RB. CHD associated with syndromic diagnoses: peri-operative risk factors and early outcomes. Cardiol Young. 2016;26: 30-52.

2. Raffa GM, Kowaleski M, Malvindi PG, Bertani A, Romano G, Sciacca S, et al Aortic surgery in Marfan patients with severe pectus excavatum. J Cardiovasc Med (Hagerstown). 2017;18:305-10.

3. Sacco Casamassima MG, Wong LL, Papandria D, Abdullah F, Vricella LA Cameron DE, et al. Modified Nuss procedure in concurrent repair of pectus excavatum and open heart surgery. Ann Thorac Surg. 2013;95:1043-9.

4. Knosalia C, Weng YG, Hammerschmidt R, Pasic M, Schmitt-Knosalla I, Grauhan O, et al. Orthotopic heart transplantation in patients with Marfan syndrome. Ann Thorac Surg. 2007;83:1691-5. 